\title{
Endothelium-dependent Coronary Response is Impaired in the Myocardium at an Early Phase of Post-infarct Remodeling
}

\author{
Tohru Hasegawa, MD, Tetsuji MiURA, MD, Akihito TsuchidA, MD, \\ Takayuki MIKI, MD, Atsushi NAKANO, MD, Atsushi KUNO, MD, \\ and Kazuaki SHIMAMOTO, MD
}

\begin{abstract}
SUMMARY
The aim of the present study was to characterize endothelium-dependent and -independent coronary functions in remodeling hearts after infarction. First, echocardiography showed that the left ventricular diastolic dimension and thickness of the non-ischemic region were increased by $25 \%$ and $20 \%$, respectively, at 2 weeks after coronary ligation in the rabbit heart. In the second series of experiments, 2 weeks after coronary ligation or a sham operation, the heart was isolated and perfused with modified Krebs-Henseleit buffer at $75 \mathrm{mmHg}$, and effluent from the pulmonary artery was measured as total coronary flow (CF). Regional CF analysis by microspheres indicated that flow to the infarcted region as a percentage of total $\mathrm{CF}$ is negligibly small. There was no significant difference between CF responses to sodium nitroprusside $\left(10^{-9}-10^{-5}\right.$ mole $\left./ l\right)$ in the sham-operated and remodeling hearts. However, the increase in $\mathrm{CF}$ after acetylcholine (ACh: $10^{-8}-10^{-5}$ mole/l) injection was significantly reduced by approximately $50 \%$ in the remodeling hearts compared to that in the sham-operated hearts. Furthermore, the percent increase in $\mathrm{CF}$ by $\mathrm{ACh}\left(10^{-5} \mathrm{~mole} / l\right)$ was inversely correlated with weight of the remodeling myocardium $(r=-0.630, p<0.05)$. These results suggest that endothelium-dependent vasodilatory function is impaired in the myocardium at the early stage of post-infarct remodeling and that this endothelial dysfunction is closely related to the degree of hypertrophy of the remodeling myocardium. (Jpn Heart J 2000; 41: 743-755)
\end{abstract}

Key words: Endothelium, Coronary flow, Ventricular remodeling, Myocardial infarction

ENDOTHELIUM-DEPENDENT vasodilatory and vasoconstrictive mechanisms play crucial roles in the regulation of blood flow. However, they are susceptible to various insults associated with hypertension, ${ }^{1-3)}$ hypercholesterolemia ${ }^{4)}$ atherosclerosis, ${ }^{5)}$ and heart failure. ${ }^{5,6)}$ Recent studies $^{(-8)}$ have shown

From the Second Department of Internal Medicine, Sapporo Medical University School of Medicine, Sapporo, Japan.

This study was supported by a grant-in-aid for Scientific Research (No. 08670812) from the Ministry of Education, Science, Sports and Culture of Japan.

Address for correspondence: Tetsuji Miura, MD, Second Department of Internal Medicine, Sapporo Medical University School of Medicine, South-1 West-16, Chuo-ku, Sapporo, Hokkaido 060-8543, Japan.

Received for publication Junuary 4, 2000.

Revised and accepted July 28, 2000. 
that endothelial function in the coronary artery is impaired in hearts failing due to chronic tachycardia and in hypertensive hearts. In remodeling hearts after infarction, it has been known for some time that time-related alteration occurs in coronary reserve, as assessed by endothelium-independent vasodilators. ${ }^{9-11)}$ However, a change in endothelium-dependent coronary vasodilatory function in the remodeling myocardium has not been well characterized. A blunted response to acetylcholine (ACh) was shown in aortic ring ${ }^{12)}$ and coronary artery ring ${ }^{13)}$ preparations from rats with infarction. However, these changes in conduit vessels may not necessarily reflect alteration in coronary arterioles, which mainly regulate the coronary blood flow level. Furthermore, it is also unknown whether endothelial dysfunction, if any, in the remodeling heart precedes or concurs with the change in endothelium-independent coronary flow reserve.

Accordingly, the present study aimed 1) to set up an in vitro preparation for analysis of coronary function in the remodeling myocardium and 2) to assess changes in endothelium-dependent and -independent coronary functions by ventricular remodeling. First, echocardiography was used to examine left ventricular remodeling after infarction in the rabbit heart in situ. Secondly, flow distribution to remodeling (non-ischemic) and infarcted (scarred) regions was determined in isolated buffer-perfused hearts using colored microspheres. Since this series of experiments indicated that the coronary flow to the infarct region is negligible, we thirdly assessed coronary flow responses to sodium nitroprusside (SNP), acetylcholine (ACh) and $\mathrm{N}^{\mathrm{G}}$-methyl-L-arginine (L-NMMA) in isolated hearts from rabbits 2 weeks after coronary ligation or a sham operation. In addition, the possible role of asymmetric dimethyl L-arginine (ADMA), an endogenous inhibitor of nitric oxide synthase (NOS), ${ }^{14,15)}$ was assessed by sampling blood from rabbits before isolation of the heart.

\section{MATERIALS AND METHODS}

This study was conducted in accordance with the Guide for the Care and Use of Laboratory Animals in Sapporo Medical University.

Experiment 1; Dimensional and functional changes in the rabbit heart in situ 2 weeks after infarction:

Surgical preparation: Male rabbits (Japanese White) weighting $1.9-2.7 \mathrm{~kg}$ were anesthetized with intravenous sodium pentobarbital $(30 \mathrm{mg} / \mathrm{kg})$ and mechanically ventilated via tracheotomy with a Harvard respirator (model 683; Harvard Apparatus, South Natick, USA) using room air and an oxygen supplement. The tidal volume was approximately $15 \mathrm{~m} l$ and the ventilation rate was 30-35 strokes per minute. The heart was exposed via a 
left thoracotomy, and 4-0 silk thread was passed around a marginal branch of the left circumflex coronary artery with a taper needle. Rabbits were divided into two groups: Remodeling group and Sham group. The coronary artery was ligated in the Remodeling group, and the coronary ligature was left untied in the Sham group. The surgical wounds were then repaired and the rabbits returned to their cages for recovery. These surgical procedures were performed under sterile conditions, and a combination of 100 $\mathrm{mg}$ ampicillin and $100 \mathrm{mg}$ cloxacilline was injected intramuscularly for prophylaxis of infection.

Echocardiography: The morphology and function of the heart were examined by echocardiography before and at 2 weeks after coronary ligation or sham operation. Two-dimensional echo images were obtained with an Aloka SSD-650CL echocardiograph using a UST-957-7.5 probe (7.5 MHz) (Aloka Co. Ltd., Tokyo, Japan). Left ventricular end-diastolic diameter (LVDd), percent fractional shortening of the left ventricle $(\% \mathrm{FS})$, interventricular septal thickness at end-diastole (IVSTd), and left ventricular postero-basal free wall thickness at end-diastole (PWTd) were measured from M-mode images. Some rabbits were sacrificed by a pentobarbital overdose at 2 weeks after surgery and their hearts excised for histological analysis. The hearts were fixed in $20 \%$ buffered formalin for $24 \mathrm{hr}$ and then stored in $10 \%$ formalin. Histological slides were prepared by standard techniques from slices of the fixed hearts and stained with hematoxylineosin and Azan stainings.

Experiment 2; Regional coronary flow in buffer-perfused rabbit hearts after infarction:

Surgical preparation and perfusion of hearts: Myocardial infarction was induced in the rabbits as in Experiment 1. Two weeks later, each rabbit was re-anesthetized and heparinized with 2,000 units of heparin. The heart was then excised and quickly mounted onto a Langendorff apparatus with a water jacket. The heart was perfused with modified Krebs-Henseleit buffer $\left(\mathrm{NaCl} 118.5, \mathrm{KCl} 4.7, \mathrm{MgSO}_{4} 1.2, \mathrm{KH}_{2} \mathrm{PO}_{4}\right.$ 1.2, $\mathrm{NaHCO}_{3} 24.8$, $\mathrm{CaCl}_{2} 2.5$, and glucose $10.0 \mathrm{mmole} / \mathrm{l}$ ) and oxygenated with $95 \% \mathrm{O}_{2}$ and $5 \% \mathrm{CO}_{2}$ at $75 \mathrm{mmHg}$. The temperature of the perfusate was maintained at $38^{\circ} \mathrm{C}$. A fluid-filled latex balloon with a PE-160 tube was inserted into the left ventricle via the left appendage and connected to a Nihon-Kohden SCK-580 pressure transducer (Nihon-Kohden, Tokyo, Japan). The balloon volume was adjusted to maintain the baseline left ventricular end-diastolic pressure (LVEDP) at less than $5 \mathrm{mmHg}$. After stabilization, the coronary artery was dilated by $10^{-5} \mathrm{~mole} / l \mathrm{SNP}$, and then 300,000 colored (yellow) microspheres (Dye-Trak, Triton Technology, San Diego, CA, USA) were 
injected as a bolus into perfusing buffer before it entered the coronary arteries. The heart was removed from the Langendorff apparatus, sliced, and separated into infarcted (i.e., scarred) and non-infarcted (i.e., remodeling) myocardium. The tissue samples were weighed and processed for coronary flow measurement.

Determination of regional coronary flow: The weighed tissue samples were digested overnight in $4 \mathrm{~mole} / \mathrm{l} \mathrm{KOH}$ with $2 \%$ Tween-80 (approximately $10 \mathrm{~m} l$ per gram). Microspheres in the solution were retained by filtering the digested sample under vacuum suction through a polyester filter (pore size $=8 \mu$ ). Then $70 \%$ ethanol was passed twice through the filter to rinse its surface. The filters containing microspheres on their surface were carefully folded and put into microtubes. A mixture of $85 \%$ volume toluene- $15 \%$ volume dimethylformamide $(200 \mu l)$ was added to each microtube to recover the dye from the microspheres. The microtubes were vortexed and centrifuged at 2,500 g for $5 \mathrm{~min}$. The supernatant solution was re-centrifuged at $2,500 \mathrm{~g}$ for $3 \mathrm{~min}$ and the photomeric absorption of each dye solution at $448 \mathrm{~nm}$ determined by a HITACHI U-1100 spectrophotometer (Hitachi, Tokyo). An index of regional flow was obtained by dividing absorbance of the dye solution by sample tissue weight. Using this flow index, coronary flow to the infarcted region as a percentage of the flow to the non-infarcted region was calculated.

Experiment 3; Coronary flow responses to ACh and SNP: Remodeling hearts versus Sham-operated hearts:

Surgical preparation: Rabbits were assigned into the sham-operated group (Sham group) or coronary ligation group (Remodeling group). As in Experiment 1, coronary ligation and sham operation were performed, and 2 weeks later, rabbits were re-anesthetized with pentobarbital and mechanically ventilated. A catheter was placed in the carotid artery and connected to a Nihon-Kohden SCK-580 pressure transducer. In some rabbits, arterial blood was sampled for assay of plasma catecholamines and ADMA. Each rabbit received 2,000 units of heparin, and the heart was then excised from each rabbit for isolated heart preparation.

Isolated rabbit heart preparation: The excised heart was perfused with modified Krebs-Henseleit buffer at $75 \mathrm{mmHg}$, and the left ventricular pressure was measured by a fluid-filled latex balloon placed in the left ventricle, as in Experiment 2. The balloon volume was adjusted to maintain baseline LVEDP at less than $5 \mathrm{mmHg}$. When spontaneous heart rate was below 210 beats per min, the heart was paced at this level by right ventricular pacing. For coronary flow measurement, the right atria were ligated and the pulmonary artery was cannulated with a polyethylene tube 
(diameter $=2.5 \mathrm{~mm}$ ) that was connected to an electromagnetic flow meter (MF V-1100, Nihon-Kohden).

Experimental protocols: After 20 minutes of equilibration, coronary flow and left ventricular developed pressure (LVDP) under baseline conditions were measured. To assess the endothelium-dependent coronary dilation, $\mathrm{ACh}$ was injected as a bolus at doses of $10^{-8}, 10^{-7}, 10^{-6}$ and $10^{-5} \mathrm{~mole} / \mathrm{l}$ into the perfusing buffer before it entered the coronary arteries. Responses of coronary flow and LVDP to each injection were recorded continuously. A sufficient interval between each ACh challenge was allowed, and recovery of these parameters to their baseline levels was confirmed. Then, endothelium-independent vasodilatory function was examined by a bolus injection of SNP at doses of $10^{-9}, 10^{-8}, 10^{-7}, 10^{-6}$ and $10^{-5} \mathrm{~mole} / \mathrm{l}$. At the end of the experiment, the heart was removed from the Langendorff apparatus, weighed, frozen, and cut into 2 -mm-thick sections from apex to base. The infarcted region and non-infarcted myocardium were traced on a clear acetate sheet, and their areas were measured by using NIH Image, an image-analysis software. The volumes of infarction (i.e., scar) and remodeling (i.e., non-ischemic) myocardium were calculated by multiplying their areas by the thicknesses of the heart slices.

Measurement of plasma catecholamine and ADMA: Each blood sample was immediately mixed with heparin and centrifuged at $1,700 \mathrm{~g}$ at $4^{\circ} \mathrm{C}$ for $30 \mathrm{~min}$ to separate plasma. Plasma was stored at $-20^{\circ} \mathrm{C}$ until catecholamine and ADMA assays. Norepinephrine and epinephrine were determined by HLC-8030 (Tohso Co. Inc., Japan), an automated highperformance liquid chromatography (HPLC) for catecholamine assay. ADMA was assayed by HPLC using orthophthalaldehyde for fluorescence determination as reported previously. ${ }^{15)}$ In brief, HPLC was performed on a Hitachi L-7110 system equipped with an F-1080 fluorescence detector (Hitachi, Tokyo) for excitation at $348 \mathrm{~nm}$ and emission at $450 \mathrm{~nm}$ with an ODS analytical-column (Senshu Kagaku, Tokyo). Samples were eluted from the column with $75 \mathrm{mM}$ sodium acetate buffer $(\mathrm{pH}=6.0)$.

Experiment 4; Effect of L-NMMA on coronary flow in remodeling hearts: Hearts with infarction and sham-operated hearts were prepared and perfused as in Experiment 3. After isolated perfused hearts were stabilized, normal Krebs-Henseleit buffer was switched to that containing $100 \mu$ mole/l LNMMA, an inhibitor of NOS. Effects of L-NMMA on coronary flow and cardiac function were recorded. L-NMMA was selected according to a study by Buxton, et al. ${ }^{16)}$ showing that this NOS inhibitor does not block muscarinic receptors in the vessel at the dose of $100 \mu$ mole $/ l$.

Chemicals: Acetylcholine chloride was obtained from Wako Pure Chem- 
ical Industries, Ltd. (Osaka, Japan). Sodium nitroprusside and L-NMMA were purchased from SIGMA (St. Louis, MO, USA).

Statistics: All results are expressed as mean \pm SEM. Differences in temporal changes of the echocardiographic parameters and coronary flow responses between sham-operated hearts and hearts with infarction were examined by two-way repeated measures analysis of variance (ANOVA). One-way ANOVA combined with Student Newman-Keuls post hoc test was used to test for differences in body weight, heart weight, and plasma levels of catecholamines and ADMA between the two groups. A $p$ value less than 0.05 was considered statistically significant.

\section{RESUlTS}

Experiment 1: In the Remodeling group, LVDd and IVSTd, which is the thickness of the non-infarcted region, significantly increased, while \%FS and PWTd, the thickness of the infarcted region, decreased 2 weeks after infarction (Table I). There were no significant changes in the ventricular dimension and function in the Sham group over the 2 weeks of followup. Histological examination revealed changes compatible to those on echocardiography. In comparison with sham-operated hearts, there was no discernible interstitial and perivascular fibrosis in the remodeling myocardium 2 weeks after infarction.

Experiment 2: Infusion of $10^{-5}$ mole/ $l$ of SNP increased coronary flow from $64 \pm 3 \mathrm{ml} / \mathrm{min}$ to $82 \pm 4 \mathrm{ml} / \mathrm{min}(n=5)$. The coronary flow (per gram of tissue) to the infarcted region under SNP infusion was $11.6 \pm$ $1.8 \%$ of the flow to the non-infarct myocardium. Since the size of the infarct was $18.7 \pm 2.6 \%$ of the left ventricular weight $(24.5 \pm 3.2 \%$ of the

Table I. Echocardiographic Data after Myocardial Infarction

\begin{tabular}{lccccc}
\hline & \multicolumn{2}{c}{ Sham $(n=5)$} & & \multicolumn{2}{c}{ Remodeling $(n=7)$} \\
\cline { 2 - 3 } \cline { 5 - 6 } & baseline & 2 weeks after operation & & baseline & 2 weeks after infaction \\
\hline LVDd (mm) & $13.9 \pm 0.4$ & $14.2 \pm 0.4$ & & $13.6 \pm 0.5$ & $17.0 \pm 0.6^{*}$ \\
\%FS & $31 \pm 2$ & $33 \pm 2$ & & $30 \pm 2$ & $22 \pm 2^{*}$ \\
IVSTd (mm) & $2.5 \pm 0.1$ & $2.3 \pm 0.0$ & & $2.3 \pm 0.1$ & $2.8 \pm 0.2^{*}$ \\
PWTd (mm) & $2.1 \pm 0.1$ & $2.3 \pm 0.1$ & & $2.3 \pm 0.1$ & $1.8 \pm 0.1^{*}$ \\
\hline
\end{tabular}

Mean \pm S.E. ${ }^{*} p<0.05$ vs baseline.LVDd $=$ left ventricular end-diastolic diameter; $\% \mathrm{FS}=$ fractional shortening of the left ventricle; IVSTd = thickness of the intraventricular septum at end-diastole; PWTd $=$ thickness of the posterobasal free wall at end-diastole. 
left ventricular volume), the flow to the infarcted region was approximately $3 \%$ of the total coronary flow under that condition.

\section{Experiment 3:}

Mortality: Of the 33 rabbits used in this series of experiments, 14 underwent a sham operation (Sham group) and 19 were subjected to coronary ligation (Remodeling group). Two rabbits in the Remodeling group died from ventricular fibrillation shortly after coronary ligation. Two rabbits in the Sham group and 5 rabbits in the Remodeling group died in their cages after surgery, probably due to atelectasis of the lungs and/ or post-operative bleeding.

Hemodynamic parameters in situ and heart weight data: Heart rate and systemic blood pressure in situ were similar in the Sham and Remodeling groups (Table II). Heart weight and heart weight-to-body weight ratio were significantly larger in the Remodeling group than in the Sham group, indicating ventricular hypertrophy in the non-infarcted region. The size of the infarct (i.e., scar) was $24.2 \pm 1.8 \%$ of the left ventricle in the Remodeling group.

Coronary flow responses to ACh and SNP: Baseline LVDP was lower in the Remodeled group than in the Sham group, while baseline heart rate and coronary flow were comparable in these two groups (Table III). Figure 1 shows the dose-response relationships of coronary flow to $\mathrm{ACh}$ and SNP. Whereas there was no significant difference in the SNP-induced coronary flow response between the Sham and Remodeling groups, the increase in the flow by ACh was significantly blunted in the Remodeling group compared to that in the Sham group. In the Sham group, coronary flow increased by $17.3 \pm 2.7 \%, 19.2 \pm 2.2 \%$ and $20.4 \pm 2.0 \%$ from baseline after injection of $10^{-7}, 10^{-6}$ and $10^{-5}$ mole/l $\mathrm{ACh}$, respectively. In the Remodeling group, however, increased coronary flows after $10^{-7}, 10^{-6}$ and $10^{-5} \mathrm{~mole} / \mathrm{l} \mathrm{ACh}$ injection were $8.0 \pm 2.5 \%, 9.7 \pm 1.5 \%$ and $10.9 \pm 2.1 \%$ from baseline, respectively ( $p<0.05$ vs the Sham group). Heart rate was maintained by right ventricular pacing and LVDP was also stable during

Table II. Hemodynamic Parameters in situ and Heart Weight Data

\begin{tabular}{lccccccc}
\hline Group & $n$ & $\begin{array}{c}\text { Heart rate } \\
(\mathrm{bpm})\end{array}$ & $\begin{array}{c}\text { Mean BP } \\
(\mathrm{mmHg})\end{array}$ & $\begin{array}{c}\mathrm{BW} \\
(\mathrm{kg})\end{array}$ & $\begin{array}{c}\mathrm{HW} \\
(\mathrm{g})\end{array}$ & $\begin{array}{c}\text { HW/BW } \\
(\mathrm{g} / \mathrm{kg})\end{array}$ & $\begin{array}{c}\text { Infarct } \\
(\% \text { of LV })\end{array}$ \\
\hline Sham & 12 & $314 \pm 10$ & $105 \pm 4$ & $2.5 \pm 0.1$ & $8.3 \pm 0.3$ & $3.3 \pm 0.1$ & --- \\
Remodeling & 12 & $311 \pm 15$ & $103 \pm 6$ & $2.6 \pm 0.1$ & $9.8 \pm 0.4^{*}$ & $3.8 \pm 0.2^{*}$ & $24.2 \pm 1.8$ \\
\hline
\end{tabular}

Mean \pm S.E. ${ }^{*} p<0.05$ vs Sham. $\mathrm{BP}=$ blood pressure; $\mathrm{BW}=$ body weight; HW = heart weight; HW / $\mathrm{BW}=\mathrm{HW}$ to $\mathrm{BW}$ ratio; $\mathrm{LV}=$ left ventricle. 
Table III. Hemodynamic Parameters before and after Injections of ACh and SNP

\begin{tabular}{|c|c|c|c|c|c|c|c|}
\hline & & \multicolumn{3}{|c|}{ Sham } & \multicolumn{3}{|c|}{ Remodeling } \\
\hline & & $\begin{array}{l}\text { Heart rate } \\
(\mathrm{bpm})\end{array}$ & $\begin{array}{l}\text { LVDP } \\
(\mathrm{mmHg})\end{array}$ & $\begin{array}{l}\text { Coronary flow } \\
(\mathrm{m} l / \mathrm{min})\end{array}$ & $\begin{array}{l}\text { Hear rate } \\
\text { (bpm) }\end{array}$ & $\begin{array}{l}\text { LVDP } \\
(\mathrm{mmHg})\end{array}$ & $\begin{array}{l}\text { Coronary flow } \\
(\mathrm{m} / / \mathrm{min})\end{array}$ \\
\hline \multicolumn{8}{|c|}{$\mathrm{ACh}($ mole $/ l)$} \\
\hline \multirow[t]{3}{*}{$10^{-8}$} & Pre-injection & $211 \pm 1$ & $127 \pm 4$ & $59 \pm 1$ & $211 \pm 1$ & $89 \pm 7^{*}$ & $56 \pm 2$ \\
\hline & Post-injection & $210 \pm 1$ & $125 \pm 4$ & $64 \pm 1$ & $211 \pm 1$ & $89 \pm 7 *$ & $60 \pm 3$ \\
\hline & $\%$ change & $-0.6 \pm 0.6$ & $-1.4 \pm 0.6$ & $8.0 \pm 1.1$ & $0.0 \pm 0.0$ & $-0.7 \pm 1.7$ & $5.3 \pm 2.5$ \\
\hline \multirow[t]{3}{*}{$10^{-5}$} & Pre-injection & $210 \pm 1$ & $125 \pm 5$ & $57 \pm 1$ & $210 \pm 0$ & $88 \pm 7^{*}$ & $56 \pm 2$ \\
\hline & Post-injection & $210 \pm 1$ & $130 \pm 6$ & $69 \pm 2$ & $210 \pm 0$ & $91 \pm 7^{*}$ & $62 \pm 3$ \\
\hline & $\%$ change & $0.0 \pm 0.0$ & $3.4 \pm 2.4$ & $20.4 \pm 2.0$ & $0.0 \pm 0.0$ & $3.0 \pm 1.0$ & $10.9 \pm 2.1^{*}$ \\
\hline \multicolumn{8}{|c|}{$\mathrm{SNP}($ mole $/ l)$} \\
\hline \multirow[t]{3}{*}{$10^{-9}$} & Pre-injection & $210 \pm 1$ & $116 \pm 4$ & $54 \pm 1$ & $210 \pm 0$ & $81 \pm 7 *$ & $49 \pm 2$ \\
\hline & Post-injection & $211 \pm 1$ & $115 \pm 4$ & $56 \pm 2$ & $210 \pm 0$ & $81 \pm 7^{*}$ & $50 \pm 2$ \\
\hline & $\%$ change & $0.5 \pm 0.5$ & $-0.7 \pm 0.5$ & $1.6 \pm 0.7$ & $0.0 \pm 0.0$ & $0.8 \pm 0.7$ & $2.1 \pm 0.9$ \\
\hline \multirow[t]{3}{*}{$10^{-5}$} & Pre-injection & $211 \pm 1$ & $116 \pm 4$ & $54 \pm 1$ & $210 \pm 0$ & $80 \pm 7 *$ & $47 \pm 2$ \\
\hline & Post-injection & $211 \pm 1$ & $117 \pm 4$ & $72 \pm 2$ & $210 \pm 0$ & $80 \pm 8^{*}$ & $61 \pm 4$ \\
\hline & $\%$ change & $0.0 \pm 0.0$ & $1.2 \pm 0.9$ & $33.2 \pm 4.0$ & $0.0 \pm 0.0$ & $0.2 \pm 1.5$ & $29.7 \pm 6.9$ \\
\hline
\end{tabular}

Mean \pm S.E. ${ }^{*} p<0.05$ vs Sham. LVDP $=$ left ventricular developed pressure.
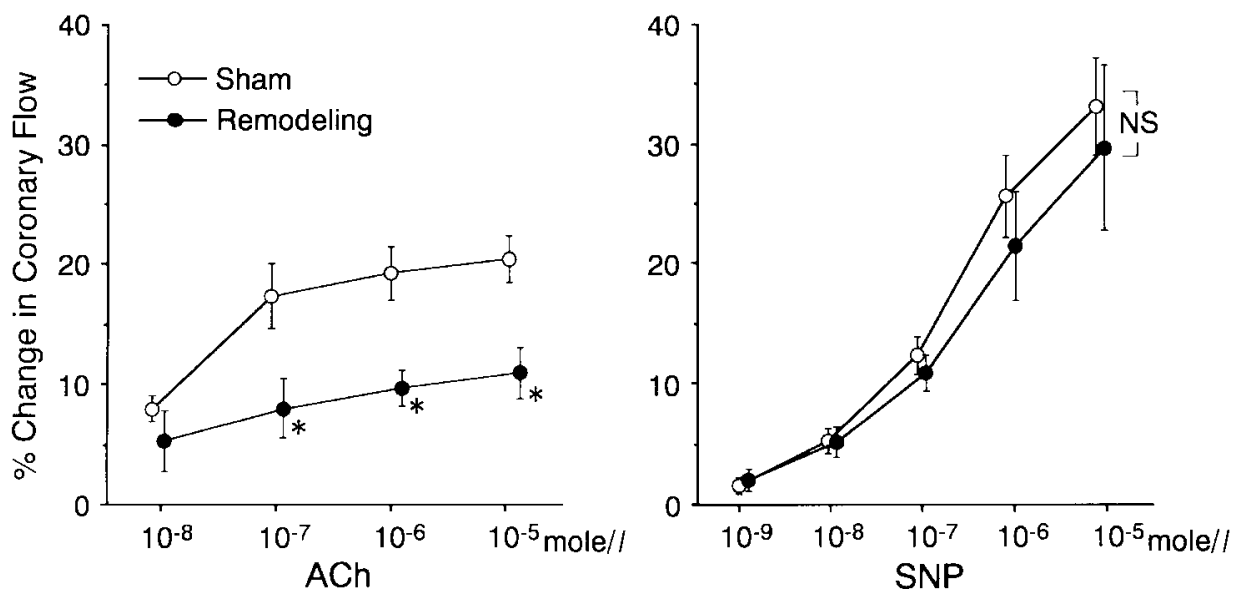

Figure 1. Percent changes in coronary flow in response to acetylcholine (ACh) and sodium nitroprusside (SNP). Coronary flow response to ACh was significantly smaller in the remodeling heart than in the shamoperated heart, while the responses to SNP were similar in these two groups. ${ }^{*} p<0.05$ by two-way repeated measures ANOVA. 


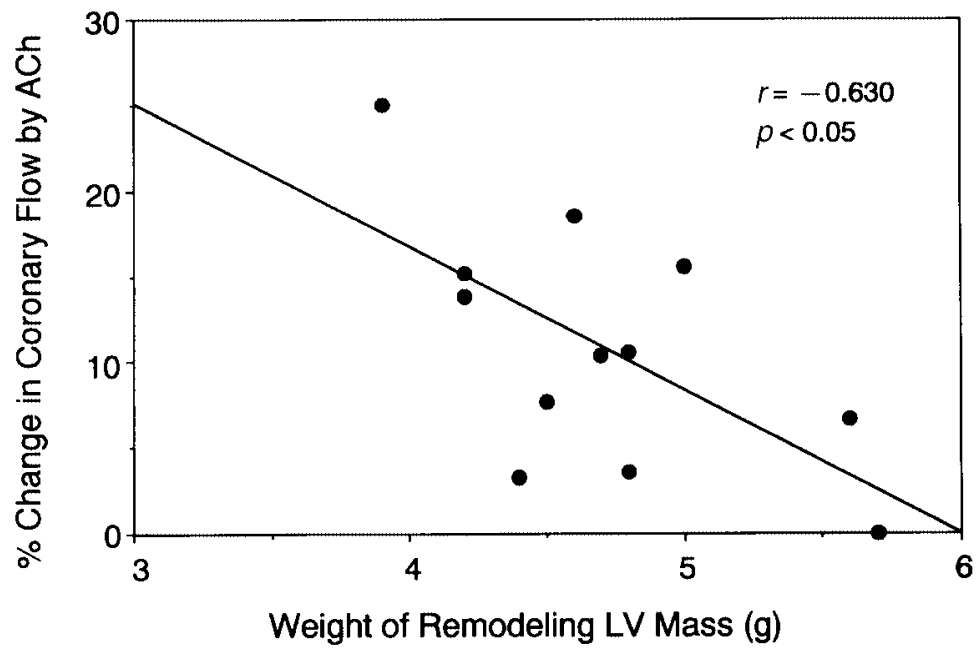

Figure 2. Relationship between coronary flow response to ACh and the mass of remodeling myocardium. Percent change in coronary flow to $10^{-5}$ mole / $l$ ACh was inversely correlated with the weight of the remodeling myocardium: $\mathrm{Y}=50.2-8.4 \mathrm{X}, r=-0.630, p=0.028$.

Table IV. Plasma Catecholamine and ADMA Levels

\begin{tabular}{lcccc}
\hline Group & $n$ & $\begin{array}{c}\text { Epinephrine } \\
(\mathrm{pg} / \mathrm{m} l)\end{array}$ & $\begin{array}{c}\text { Norepinephrine } \\
(\mathrm{pg} / \mathrm{m} l)\end{array}$ & $\begin{array}{c}\text { ADMA } \\
(\mu \mathrm{mole} / l)\end{array}$ \\
\hline Sham & 6 & $24.4 \pm 9.0$ & $251.0 \pm 50.3$ & $0.79 \pm 0.07$ \\
Remodeling & 5 & $48.2 \pm 14.3$ & $405.0 \pm 123.1$ & $0.98 \pm 0.02^{*}$ \\
\hline
\end{tabular}

Mean \pm S.E. $* p<0.05$ vs Sham. ADMA=asymmetric dimethyl L-arginine.

Table V. Effects of L-NMMA on Coronary Flow and LVDP

\begin{tabular}{lcccccc}
\hline Group & $n$ & \multicolumn{2}{c}{ Baseline } & & \multicolumn{2}{c}{ L-NMMA $(100 \mu \mathrm{mole} / l)$} \\
\cline { 3 - 4 } \cline { 6 - 7 } & & $\begin{array}{c}\text { Coronary Flow } \\
(\mathrm{m} l / \mathrm{min} / \mathrm{g})\end{array}$ & $\begin{array}{c}\text { LVDP } \\
(\mathrm{mmHg})\end{array}$ & & $\begin{array}{c}\text { Coronary Flow } \\
(\mathrm{m} l / \mathrm{min} / \mathrm{g})\end{array}$ & $\begin{array}{c}\text { LVDP } \\
(\mathrm{mmHg})\end{array}$ \\
\hline Sham & 8 & $9.9 \pm 0.8$ & $121 \pm 5$ & & $6.7 \pm 0.6 \#$ & $99 \pm 5 \#$ \\
Remodeling & 8 & $9.5 \pm 0.5$ & $93 \pm 8^{*}$ & & $6.4 \pm 0.6 \#$ & $86 \pm 7 \#$ \\
\hline
\end{tabular}

Mean \pm S.E. ${ }^{*} p<0.05$ vs Sham, $\# p<0.05$ vs Baseline. LVDP $=$ left ventricular developed pressure.

ACh and SNP injection (Table III). Although heart rate and LVDP data were presented only for the lowest and the highest doses of ACh/SNP in Table III, these parameters were stable during injection of the other doses of $\mathrm{ACh} / \mathrm{SNP}$ as well (data not shown). To assess the relationship between the extent of ventricular remodeling and the change in coronary response to $\mathrm{ACh}$, the increase in coronary flow by $\mathrm{ACh}\left(10^{-5} \mathrm{~mole} / \mathrm{l}\right)$ in each heart 
was plotted against the remodeled ventricular mass (i.e., the ventricular weight from which the scarred infarct region was subtracted). As shown in Figure 2, there was a significant inverse linear relationship between these two parameters $(\mathrm{Y}=50.2-8.4 \mathrm{X}, \mathrm{r}=-0.630, p<0.05)$.

Plasma catecholamine and ADMA: Catecholamines and ADMA levels in the blood sampled immediately before heart excision are summarized in Table IV. Although plasma norepinephrine and epinephrine levels tended to be higher in the Remodeling group than in the Sham group, the differences did not reach statistical significance. On the other hand, the plasma ADMA level in the Remodeling group was slightly higher than that in the Sham group.

Experiment 4: Hemodynamic data in situ in the Sham and Remodeling groups were comparable with those obtained in Experiment 3 (data not shown). Baseline coronary flows per gram of tissue in the two groups were similar, and there were no significant differences in reduction of coronary flow and that of LVDP by $100 \mu$ mole/ $l$ L-NMMA between the sham-operated and remodeling hearts (Table V).

\section{DISCUSSION}

Endothelium-dependent and -independent coronary vasodilatation in the remodeling myocardium after infarction: In the present study, coronary flow responses to SNP were similar in the control (i.e., sham-operated) and remodeling hearts (Figure 1), indicating that the endothelium-independent coronary reserve remains unchanged at 2 weeks after infarction. This finding is consistent with earlier observations in the rat model of infarction 1 or 3 weeks after infarction. ${ }^{10,11)}$ However, the same studies ${ }^{10,11)}$ and others ${ }^{9)}$ found that the coronary flow reserve assessed by endothelium-independent vasodilators was significantly reduced at 4 or 8 weeks after infarction, when the myocyte hypertrophy appears disproportional to angiogenesis. ${ }^{11)}$ Therefore, it is likely that the absence of change in coronary flow response to SNP at 2 weeks after infarction is a phenomenon of the early phase of ventricular remodeling in the rabbit heart.

In contrast with the response to SNP, the increase in coronary flow after ACh infusion was significantly reduced in the remodeling heart (Figure 1). At the time of ACh infusion, left ventricular systolic pressure, which could have increased extravascular resistance during systole, was rather low in the remodeling heart. Furthermore, the coronary flow response to $\mathrm{ACh}$ was inversely correlated with the remodeling ventricular mass (Figure 2). These results indicate that dysfunction of endothelium- 
dependent coronary vasodilation is associated with the extent of ventricular remodeling. Recently, Qi, et al. ${ }^{17)}$ reported that the coronary flow response to serotonin was significantly blunted in the rat heart 4 weeks after infarction, although they did not assess endothelium-independent coronary reserve. Taken together with the findings by SNP, the present results suggest that endothelium-dependent coronary vasodilation is impaired even before reduction in the endothelium-independent reserve during progression of post-infarct ventricular remodeling.

Mechanism of endothelial dysfunction in the remodeling myocardium: The mechanism of endothelial dysfunction in the remodeling heart cannot be ascertained from the present experiments. However, the finding that reduction of coronary flow by L-NMMA was similar in the sham-operated and remodeling hearts suggests that the baseline nitric oxide (NO) level in the coronary vessels may not be substantially changed by remodeling. Although there was a slight elevation of plasma ADMA level in the rabbit with remodeling, it was still below $\mathrm{IC}_{50}$ (i.e., $2-5 \mu$ mole $/ l$ ), ${ }^{18}$ ) and the difference in ADMA level is unlikely to induce a substantial difference in the NOS activity. However, these results do not necessarily indicate that NO production from the endothelium is normal in the remodeled heart. An apparently normal NO level under baseline conditions in the remodeling heart can be a result of enhanced NO inactivation by free radicals ${ }^{19,20}$ ) and compensatory up-regulation of an NO-producing mechanism. If that is the case, activation of muscarinic receptors by ACh may fail to increase the tissue NO level in the remodeling myocardium to the level of that in the normal heart. A recent study by Bauersachs, et al. ${ }^{12)}$ supports this notion. They found that eNOS protein expression and mRNA expression are actually up-regulated in the aorta 8 weeks after myocardial infarction. Moreover, the relaxation response of the aortic ring to ACh was significantly attenuated after infarction, and superoxide dismutase, a superoxide radical scavenger, substantially restored endothelium-dependent relaxation in that preparation. These findings suggest that inactivation of NO by over-produced superoxide may cancel the enhanced NO production by upregulated eNOS in the aorta after myocardial infarction. The same mechanism might underlie the blunted coronary flow response to $\mathrm{ACh}$ in the myocardium with post-infarct remodeling (Figure 1).

Another possible explanation for the attenuated response to $\mathrm{ACh}$ in the remodeling heart is reduced production of other ACh-induced vasodilatory mediators (i.e., prostacyclin and endothelium-derived hyperpolarizing factor [EDHF] $)^{21)}$ Although it is not known whether EDHF in the coronary arteries is altered after infarction, impairment of EDHF-mediated vasodi- 
lation has been shown in the mesenteric artery of diabetic rats ${ }^{22}$ and in the gastroepiploic arteries of aged or hypercholesterolemic humans. ${ }^{23}$ ) Since EDHF plays an important role in the regulation of coronary resistance, particularly in the small arterioles, ${ }^{24)}$ the effects of post-infarct remodeling on EDHF production may warrant further investigation.

Methodological limitations: To assess the coronary flow level to the remodeling myocardium in an isolated heart preparation, an obvious problem is differentiation of the flow to the remodeling region from flow to the region of healing infarct. In this study, determination by microspheres indicated that flow to the 2-week-old infarct was less than $3 \%$ of total coronary flow under infusion of $10^{-5} \mathrm{~mole} / l \mathrm{SNP}$. The increase in coronary flow in response to SNP was approximately 30\% (Figure 1), which is similar to the reactive hyperemic flow after 60 seconds of zero-flow ischemia in the same preparation (unpublished observation). Thus, even if we assume that coronary flow to the infarcted region does not respond to SNP at all, the flow to that region under baseline conditioning would be no more than $5 \%$ of the total coronary flow. Therefore, in the present preparation, coronary flow to the infarcted region appears to be negligible, and total coronary flow was used an index of flow to the remodeled myocardium.

Another limitation in the present study was the inability to differentiate contributions of ventricular remodeling per se and heart failure to the coronary endothelial dysfunction. Attenuated coronary response to ACh has been demonstrated in the canine heart failed by rapid ventricular pacing. $\left.{ }^{6}\right)$ However, in contrast with that canine model of heart failure, neither overt signs of heart failure nor changes in the systemic hemodynamic parameters in situ were observed in the present rabbit model of remodeling. Furthermore, the elevations of plasma catecholamines were modest. These findings and the close correlation between the coronary flow response to $\mathrm{ACh}$ and remodeling muscle mass (Figure 2) suggest that the remodeling of the heart per se may have contributed to the endothelial dysfunction.

In summary, endothelium-dependent coronary response is impaired in the heart at the early stage of post-infarct remodeling, while its endothelium-independent coronary reserve is unchanged. This endothelial dysfunction is closely related with the degree of hypertrophy. 


\section{REFERENCES}

1. Fujii K, Tominaga M, Ohmori S, et al. Decreased endothelium-dependent hyperpolarization to acetylcholine in smooth muscle of the mesenteric artery of spontaneously hypertensive rats. Circ Res 1992; 70: 660-9.

2. Lyons D, Webster J, Benjamin N. The effect of antihypertensive therapy on responsiveness to local intra-arterial $\mathrm{N}^{\mathrm{G}}$-monomethyl-L-arginine in patients with essential hypertension. J Hypertens 1994; 12: 1047-52.

3. Boulanger CM. Secondary endothelial dysfunction: hypertension and heart failure. J Mol Cell Cardiol 1999; 31: 39-49.

4. Egashira K, Inou T, Hirooka Y, et al. Impaired coronary blood flow response to acetylcholine in patients with coronary risk factors and proximal atherosclerotic lesions. J Clin Invest 1993; 91: 29-37.

5. Shimokawa H. Primary endothelial dysfunction: atherosclerosis. J Mol Cell Cardiol 1999; 31: 23-37.

6. Wang J, Seyedi N, Xu XB, Wolin MS, Hintze TH. Defective endothelium-mediated control of coronary circulation in conscious dogs after heart failure. Am J Physiol 1994; 266: H670-80.

7. Treasure CB, Klein LK, Vita JA, et al. Hypertension and left ventricular hypertrophy are associated with impaired endothelium-mediated relaxation in human coronary resistance vessels. Circulation 1993; 87: 86-93.

8. Crabos M, Coste P, Paccalin M, et al. Reduced basal NO-mediated dilation and decreased endothelial NO-synthase expression in coronary vessels of spontaneously hypertensive rats. J Mol Cell Cardiol 1997; 29: 55-65.

9. Karam R, Healy BP, Wicker P. Coronary reserve is depressed in postmyocardial infarction reactive cardiac hypertrophy. Circulation 1990; 81: 238-46.

10. Nelissen-Vrancken HJMG, Debets JJM, Snoeckx LHEH, Daemen MJAP, Smits JFM. Time-related normalization of maximal coronary flow in isolated perfused hearts of rats with myocardial infarction. Circulation 1996; 93: 349-55.

11. Kalkman EA, Bilgin YM, van Haren P, van Suylen, RJ, Saxena PR, Schoemaker RG. Determinants of coronary reserve in rats subjected to coronary artery ligation or aortic banding. Cardiovasc Res 1996; 32: 1088-95.

12. Bauersachs J, Bouloumié A, Fraccarollo D, Hu K, Busse R, Ertl G. Endothelial dysfunction in chronic myocardial infarction despite increased vascular endothelial nitric oxide synthase and soluble guanylate cyclase expression: role of enhanced vascular superoxide production. Circulation 1999; 100: 292-8.

13. Feng Q, Lu X, Fortin AJ, et al. Elevation of an endogenous inhibitor of nitric oxide synthesis in experimental congestive heart failure. Cardiovasc Res 1998; 37: 667-75.

14. Böger RH, Bode-Böger SM, Szuba A, et al. Asymmetric dimethylarginine (ADMA): a novel risk factor for endothelial dysfunction: its role in hypercholesterolemia. Circulation 1998; 98: 1842-7.

15. Matsuoka H, Itoh S, Kimoto M, et al. Asymmetrical dimethylarginine, an endogenous nitric oxide synthase inhibitor, in experimental hypertension. Hypertension 1997; 29 [part 2]: 242-7.

16. Buxton ILO, Cheek DJ, Eckman D, Westfall DP, Sanders KM, Keef KD. N ${ }^{\mathrm{G}}$-Nitro L-arginine methyl ester and other alkyl esters of arginine are muscarinic receptor antagonists. Circ Res 1993; 72: 387-95.

17. Qi XL, Stewart DJ, Gosselin H, et al. Improvement of endocardial and vascular endothelial function on myocardial performance by captopril treatment in postinfarct rat hearts. Circulation 1999; 100: 1338-45.

18. Leiper J, Vallance P. Biological significance of endogenous methylarginines that inhibit nitric oxide synthases. Cardiovasc Res 1999; 43: 542-8.

19. Belch JJF, Bridges AB, Scott N, Chopra M. Oxygen free radicals and congestive heart failure. Br Heart J 1991; 65: 245-8.

20. Tschudi MR, Mesaros S, Lüscher TF, Malinski T. Direct in situ measurement of nitric oxide in mesenteric resistance arteries: Increased decomposition by superoxide in hypertension. Hypertension 1996; 27: 32-5.

21. Ming Z, Parent R, Lavallee M. Nitric oxide-independent dilation of conductance coronary arteries to acetylcholine in conscious dogs. Circ Res 1997;81:977-87.

22. Fukao M, Hattori Y, Kanno M, Sakuma I, Kitabatake A. Alterations in endothelium-dependent hyperpolarization and relaxation in mesenteric arteries from streptozotocin-induced diabetic rats. Br J Pharmacol 1997; 121: 1383-91

23. Urakami-Harasawa L, Shimokawa H, Nakashima M, Egashira K, Takeshita A. Importance of endotheliumderived hyperpolarizing factor in human arteries. J Clin Invest 1997; 100: 2793-9.

24. Nishikawa Y, Stepp DW, Chilian WC. In vivo location and mechanism of EDHF-mediated vasodilation in canine coronary microcirculation. Am J Physiol 1999; 277: H1252-9. 